\title{
The syntax, pragmatics, and prosody of parenthetical what ${ }^{1}$
}

\author{
NICOLE DEHÉ andYORDANKA KAVALOVA \\ University College London \\ (Received 10 October 2005; revised 13 March 2006)
}

This article contributes to the discussion of parentheticals. It focuses on a specific oneword parenthetical in English, namely what. To account for its distributional behaviour we offer a multifaceted approach. Specifically, our study explains why parenthetical what strongly prefers the position immediately preceding a cardinal number. In this respect, we identify three key questions which can only be answered collectively by looking into its syntactic properties, semantic and pragmatic motivation, and prosodic characteristics. While syntax accounts for parenthetical what being attached to the node that dominates the number, pragmatics takes care of its position immediately preceding the number, and prosody explains the unacceptability of what in sentence-initial position. In this way, this study supports the idea that to fully account for the behaviour of parenthetical structures, the phenomenon should not be restricted to a single component of the grammar. The strength of the present approach also lies in the authenticity and amount of data we used.

\section{Introduction}

This article deals with a particular usage of what which, based on its behaviour and characteristics, we refer to as 'parenthetical' what. Examples are given in (1) through

(3) below (parenthetical what is in italics here and throughout the article).

(1) I've been dreaming of winning a gold medal for what 20 years now (The Greatest TV Treats of 2004, Channel 4, 26 December 2004)

(2) After writing what ten novels of suspense and then one novel as a kind of a bridge passage you've moved into historical fiction (ICE-GB: s1b-048, \#190)

(3) You spend what 17,000 pounds on one of these. What you actually buy is that, the badge. (Top Gear, BBC2, 26 December 2004).

The study is based on roughly eighty examples of this kind from two different types of sources. About half of our examples are drawn from the spoken part of the British Component of the International Corpus of English (ICE-GB; 1990s) and from

\footnotetext{
${ }^{1}$ An earlier version of this paper was presented at the 1st International Conference on the Linguistics of Contemporary English at the University of Edinburgh in June 2005. We would like to thank the audience there for the lively discussion. Parts of this paper were also presented at the University of Konstanz in May 2005 and the University of Göttingen in July 2005 by Nicole Dehé. We are grateful to the audiences there for discussion and comments. Furthermore, we would like to thank the following people who have contributed in various ways to the work presented here: Bas Aarts, Carolyn Biraben, Diane Blakemore, Dirk Bury, Ray Jackendoff, Ad Neeleman, Rosa Vega-Moreno, and Anne Wichmann, as well as one anonymous reviewer for $E L L$. The present work was supported by DFG grant DE 876/1-1 to Nicole Dehé, as well as an ORS grant and a Stern scholarship from the University of London to Yordanka Kavalova.
} 
the Diachronic Corpus of Present-day Spoken English (DCPSE; 1960s/1990s). ${ }^{2}$ The corpora texts are accompanied by corresponding sound files which proved extremely valuable for the present research, especially for the results discussed in sections 3 and 4 . The other half of the examples are observed examples which were collected mostly from the media between 2004 and 2005 by the authors. Some of these examples were recorded and digitized into individual sound files for use in the analysis. Due to the nature of these sources, our data set is of a considerable breadth of coverage and allows for a representative account of the topic under investigation.

Based on our data set, the most typical places of interpolation for parenthetical what are as given in (4) through (7) below in no particular order: between a syntactic head (V or P) and its nominal complement (cf. (4) and (5)), within a noun phrase (cf. (6)), and between a copula and a predicate (cf. (7)). ${ }^{3}$

(4) Between a verb (V) and its complement

(a) I don't think she really thinks we're paying what seventy-five pence for a gallon (DCPSE, DL-B13, \#175)

(b) But Hooper bowled what sixteen overs at the end (ICE-GB: s1a-095, \#80)

(5) Between a preposition (P) and its complement

(a) because it's surely quite difficult these days to persuade an actor or actress to commit themselves for what six to eight months ... (ICE-GB: s1b-050, \#72)

(b) There is no 'unless' coz no one has said 'whoopsy daisies' for what 50 years and even then it was uhm it was just little girls with blonde ringlets (Julia Roberts in Notting Hill)

(6) Within an NP

(a) uh you get it out of the computer every what six months or something and have a look at it (DCPSE: DL-B14, \#525)

(b) I mean considering they're only seventeen and they're likely to be together for another uh what fifty sixty years (DCPSE: DL-B35, \#107)

(7) Between a copula and a predicate

(a) in Russian there are what ninety-something basic ways of conjugating a verb (DCPSE: DL-B23, \#1076)

(b) It's been what seven years. (quiz master to a contestant who had tried for seven years to get on the show Who wants to be a millionaire?, ITV1, 27 November 2004)

Notice at this stage that these examples illustrate another important aspect of the distribution of parenthetical what. Regardless of whether it is placed between head and

${ }^{2}$ Both these corpora have been developed at the Survey of English Usage, University College London. More information is available from this link: http://www.ucl.ac.uk/english-usage/. For ICE-GB, cf. also Nelson, Wallis \& Aarts (2002). Note that the spoken material in both corpora is not marked by any punctuation. In this article, we use the examples as they appear in the corpora. Also, the sentence numbers of the examples from DCPSE may differ from the reference numbers in the final version of the corpus. This is because we used a beta-release of DCPSE for this study.

${ }^{3}$ Note that it has been argued, at least for some parentheticals, that they are not typically wedged between a head and a nominal complement (e.g. Peterson, 1999: 239). However, as Peterson (1999: 239-40) suggests, this constraint on parenthetical position could be a matter of syntactic weight and stress, rather than anything else. Since what is short and light, it can easily appear in this position. 
complement or between copula and predicate, it always surfaces in a position preceding a number (e.g. seventy-five in (4a), sixteen in (4b)).

From the typical distribution of parenthetical what illustrated here, it becomes immediately obvious that parenthetical what is fundamentally different from other, better-known usages of the same form, such as (interrogative or nominal relative) pronouns (cf. (8) and (9), respectively), (interrogative or exclamative) determiners (cf. (10) and (11)), or what in echo-questions (cf. (12)).

(8) (a) What was the point of the last paragraph (ICE-GB: s1b-069, \#177)

(b) And what is the referee's decision (ICE-GB: s2a-014, \#195)

(9) (a) That's not what John Major thinks (ICE-GB: s1b-039, \#62)

(b) We don't know what will happen but we can only sort of work and see what happens (ICE-GB: s1a-002, \#109)

(10) (a) Well what books shall I bring along (ICE-GB: s1a-043, \#103)

(b) First of all to what companies does that scheme apply (ICE-GB: s1b-062, \#88)

(11) (a) And what a mighty building this is (ICE-GB: s2a-027, \#79)

(b) What a beautiful piece of rugby there from Schofield (ICE-GB: s2a-004, \#283)

(12) (a) Do I want what? (ICE-GB: s1b-080, \#175)

(b) B: She does heaps of hours.
A: Heaps of what?
C: Hours.
A: Oh, do you?
D: Yes.
(ICE-GB: s1a-019, \#228-232)

In fact, parenthetical what differs from its homonyms not only in terms of its distribution, but also in other key properties. For example, we assume that parenthetical what, as opposed to its interrogative counterparts, has no interrogative feature (cf. section 3 ). Instead, it comes with a feature of its own which is to be specified below (section 2). Similarly, its functions in utterance interpretation (section 3 ) and its prosodic characteristics (section 4) clearly diverge from those of other kinds of what. We will occasionally refer to these differences in behaviour between parenthetical what, on the one hand, and other types of what, on the other hand, at appropriate stages as we move along, but we trust that since they are so obvious in nature, a detailed discussion is not necessary.

In what follows, we comprehensively account for the syntactic distribution of parenthetical what and explain its function in utterance interpretation by looking at its syntactic, pragmatic, and prosodic characteristics. With respect to syntax, we will argue that, just like other parentheticals, parenthetical what is syntactically independent from its host structure. It owes its surface position in the immediate vicinity of a number to a feature-matching process operating independently from the internal syntax of the host. However, its linear preference, the position immediately preceding the number, cannot be accounted for along syntactic lines. We argue that this positional preference of parenthetical what can be explained in terms of its pragmatic functions. Parenthetical what is employed to ease the process of interpretation and to ensure that the hearer reaches the contextual assumptions necessary for a most faithful interpretation of the 
speaker's thoughts. We will demonstrate that it usually occurs in front of a focused constituent and will relate this to its function with respect to the numeral in the focused structure. To address the speaker's motivation for inserting parenthetical what in his/her utterance, we refer to the Principle of Relevance as formulated in the Relevance Theory framework (Sperber \& Wilson, 1995). Interactionally, this parenthetical functions as a floor-keeping device and regulates the process of communication. With respect to prosody, we will show that parenthetical what is either surrounded or followed by pauses, it is typically realized on low-level pitch, and it affects the prosody of its host with regard to phrasing, but not with respect to the overall pitch declination. The prosodic characteristics of what, in particular its effect on the phrasal prosodic structure of its host, also account for another distributional characteristic: parenthetical what cannot occur clause- or sentence-initially (cf. section 2). In a nutshell, this is because what has to join preceding material to form a prosodic phrase, but clearly cannot do so if it is situated in initial position.

In short, by bringing together evidence from the syntactic, pragmatic, and prosodic aspects of parenthetical what, we can fully account for its particular distribution, specifically for the fact that it (almost) always occurs in front of a number and never sentence-initially.

The remainder of the article is organized as follows. Section 2 addresses the syntactic properties of parenthetical what and the corresponding syntactic analysis. Section 3 deals with its pragmatic characteristics, while section 4 offers an account of its prosodic properties. Section 5 offers some concluding remarks on the status of parentheticals in general and parenthetical what in particular.

\section{Syntax}

For many years, there have been two main approaches to the syntax of parentheticals, each contradicting the other. While the first approach holds that parentheticals are syntactically integrated into the structure in which they occur (cf., e.g., Corver \& Thiersch, 2002; Emonds, 1973; Jackendoff, 1977; McCawley, 1982; Potts, 2002; Ross, 1973), the second maintains that parentheticals are syntactically unrelated to the syntax of the host structure (cf., e.g., Espinal, 1991; Haegeman, 1988; Peterson, 1999). However, as Ackema \& Neeleman (2004) argue, neither of the two approaches is entirely satisfactory. We will address both approaches in turn, and outline the respective behaviour of what. ${ }^{4}$

To begin, Ackema \& Neeleman (2004: 97) note that if the parenthetical is syntactically integrated in the host, it is essentially an adjunct. (There is no reason

\footnotetext{
${ }^{4}$ Note that within the two groups, accounts vary. For example, within the integrationist accounts, different structural analyses have been suggested, and the relation between syntactic structure and semantic representation has been approached in different ways. Moreover, Haegeman (1988) seems to draw a stricter line between syntax and utterance interpretation than, e.g., Espinal (1991) does. However, in principle, the two main ideas are predominant in the literature and it is beyond the scope of this article to address each contribution in any more detail than we do below.
} 
to assume, nor has anyone argued, that parentheticals can be syntactic heads, or be a part of the respective argument structure.) Consequently, just like adjuncts, parentheticals should be visible for certain syntactic operations in the host. However, as is already widely accepted, parentheticals, unlike adjuncts, cannot undergo movement, be questioned, or become the focus of an it-cleft construction (cf. Espinal, 1991: 729ff; Haegeman, 1988: 233; Quirk, Greenbaum, Leech \& Svartvik, 1985: 504ff). In addition, as demonstrated for example in Espinal (1991), only adjuncts, but not parentheticals, can count as first constituents in verb-second languages where the verb must appear after the first constituent in main clauses. In general, parentheticals do not take part in any syntactic operations applying in the host structure. The examples given in (13) through (16) illustrate that parenthetical what is not exceptional in this respect. For instance, what cannot be the focus of an it-cleft (cf. (13)).

(13) It-cleft

(a) After writing what ten novels of suspense and then one novel as a kind of a bridge passage... (cf. (2) above)

(b) *It is what that he wrote ten novels of suspense.

Similarly, constituent tests reveal that what is not part of the syntactic structure of the host. Looking at the distribution as illustrated in the introduction to this article, it seems at least possible at first sight that what forms a constituent with the syntactic material following it, e.g., that it is part of a verbal or prepositional complement or of a predicate in a copula construction. This seems even more worth exploring because Corver $\&$ Thiersch (2002: 14-15) argue that parenthetical clauses form 'a constituent with the phrasal host to which [they are] attached'. However, the examples in (14) through (16) suggest the opposite. For example, while a verbal complement can be fronted (as shown by (14b)), what cannot move along (cf. (14c)). At the same time, it cannot stay behind either (cf. (14d)).

(14) Fronting

(a) He wrote what ten novels of suspense before he went to law school.

(b) Ten novels of suspense he wrote before he went to law school.

(c) *What ten novels of suspense he wrote before he went to law school.

(d) *Ten novels of suspense he wrote what before he went to law school.

Furthermore, as shown in (15) and (16), what cannot be part of a sentence fragment. In (15), the verbal complement is questioned and it occurs as a grammatical sentence fragment in answer A2. As shown by A3, adding what to this sequence renders the sentence fragment ungrammatical. In (16), the number is the focus of the question. The number alone can occur as a sentence fragment (as in A2), but it cannot be accompanied by parenthetical what (cf. A3).

(15) Sentence fragments I

Q: What did he write?

A1. He wrote what ten novels of suspense.

A2. Ten novels of suspense.

A3. ${ }^{*}$ What ten novels of suspense. 
(16) Sentence fragments II

Q: How many novels did he write?

A1. He wrote what ten.

A2. Ten.

A3. *What ten.

From the evidence given along the lines of examples (13) through (16), we conclude that what does not form a constituent with any sequence in the host structure or take part in syntactic operations applying in the host. It seems fair to assume then that what, just like other parentheticals, is not structurally integrated in the host.

This conclusion seems to suggest that the second approach to the syntax of parentheticals is correct: parentheticals are not structurally integrated in the host structure at any level of representation, but are generated separately, and related to the host structure by a discourse-governed process of linearization only. Haegeman (1988) argues that interpretation of the parenthetical is accounted for in terms of processing. The respective cue is intonation, which is argued to be essentially comma intonation, a 'syntactically determined PF property of parentheticals' (Haegeman, 1988: 250). However, if the parenthetical is syntactically not integrated, the prediction is that there is no syntactic relation whatsoever between parenthetical and host, which is not generally true, as has previously been shown by Hoffmann (1998) and Ackema \& Neeleman (2004: 98-9). These authors present relevant data, some of which are repeated in (17) and (18) below, which show that there can be a syntactic relationship between parenthetical and host. In the examples in (17), borrowed from Hoffmann (1998: 302; our glosses), the interpolated parentheticals contain reflexive pronouns which need to be bound by an antecedent. In both (17a) and (17b), the relevant antecedent is a major constituent in the host clause. In (17a), the reflexive sich is bound by the matrix subject Hanna, while in (17b), sich is bound by the object of the matrix clause, i.e. the pronoun ihn.

(17) (a) Hanna hat, sich nicht schonend, die Arbeit zu Ende gebracht. Hanna has herself not sparing the work to end brought 'Hanna has finished the work without sparing herself.'

(b) Hanna hat ihn, sich nicht schonend, bei der Arbeit gesehen. Hanna has him himself not sparing with the work seen 'Hanna has seen him working. He didn't spare himself.'

Along similar lines, Ackema \& Neeleman (2004: 98-9) show that parentheticals can contain parasitic gaps that are licensed by $\mathrm{A}^{\prime}$-movement in the host clause, and that they can be secondary predicates that take a DP in the host structure for subject (cf. (18) for the latter). In (18a), the parenthetical is a secondary predicate which takes the DP Jan for subject. This DP also functions as subject in the host structure. (18b) shows that this is not just a matter of interpretation, because as elsewhere, the c-command restriction on predication holds.

(18) (a) Jan, naakt en dronken, stond weer op de deur te bonken.

John, naked and drunk stood again on the door to bang

'John, naked and drunk, was banging on the door again.' 
(b) * Met Jan, naakt en dronken, valt niet te praten. With John naked and drunk falls not to speak 'When he is naked and drunk it is impossible to talk to John.'

Ackema \& Neeleman (2004: 99) conclude from this that 'a parenthetical cannot affect the syntax of the host clause, but grammatical requirements imposed by material in the parenthetical can be satisfied by elements in the host clause'. Even though this may not hold for all (types of) parentheticals, we follow Ackema \& Neeleman in that parentheticals can introduce a property or syntactic feature which remains unsatisfied within its internal syntactic structure, but can be satisfied by elements in the host clause. ${ }^{5}$

We believe that there is a syntactic relationship between parenthetical what and the host clause which can be expressed along similar lines. While it cannot function as a constituent in the host structure, what is at the same time syntactically not completely independent. Due to the nature of what, this may at first glance seem hard to test. Clearly, what cannot be tested for binding relations, parasitic gaps, and the like. However, remember the strict preference of parenthetical what to occur in a position immediately preceding a cardinal number or, rather infrequently, a modified number such as around seven in (19f). The sequence $<$ what $\mathrm{NUM}>$ is the observed pattern in 95 per cent of our data. For illustration, consider the additional examples in (19). The relevant cardinal numbers have all been underlined for convenience. ${ }^{6}$

(19) (a) we're a fairly small group because there's only what four of us (DCPSE: DL-A08, \#546)

(b) and a commercial bank lends out what seven or eight times its assets, on the principle that everybody doesn't call for their money on the same day (DCPSE: DL-E04, \#79)

(c) I mean considering they're only seventeen and they're likely to be together for another uh what fifty sixty years (DCPSE: DL-B35, \#107)

(d) ... but what I have an objection to is the European Union deciding collectively that it is going to put 40 per cent of its budget into an area where you have got what 2 per cent of the employment (Tony Blair on farming subsidies in the EU; Channel 4 News, 14 June 2005)

${ }^{5}$ We are aware of the fact that a great number of parentheticals come without such an unsatisfied feature, cf. for example the vocative in (i):

(i) $\ldots$ it seems to me that politicians, Terry, underestimate the voters. (ICE-GB: s1b-029, \#70)

In extreme cases, there is neither a syntactic nor a discourse relation between the interpolated string and the host utterance (cf. (ii)):

(ii) And what we found was uhm could you turn the slide projector off please uhm very substantial mortality differences within the population (ICE-GB: s2a-047, \#110)

However, it is undeniable that there can be a syntactic relationship between parenthetical and host, as illustrated in (17) and (18) above, and crucially, the relation is unidirectional in that the parenthetical feature can be satisfied by an element in the host, but not vice versa.

${ }^{6}$ Note that the remaining percentage of data includes what we would like to refer to as 'number-related' expressions. Examples are given in (i) and (ii):

(i) He comes down what occasionally (DCPSE: DL-CO4, \#318)

(ii) You've got a great body of stuff which has grown up lovely over the last what so many years (DCPSE: DL-B16, \#414) 
(e) JC: So what we've got here is one of the most famous racing cars of all time the Ford GT40...

JM: And what we have here is the Noble M400 which is one of our favourite current sports cars...

JC ... So, what do we think? What do we reckon is gonna win this?

A: The Noble.

JC: You reckon the Noble? An interesting one that because it's got what $425 \mathrm{bhp}$.

The Ford only has 390. (Top Gear, BBC2, 19 December 2004)

(f) There are two high waters at London Bridge tomorrow, one at what around seven o'clock in the morning, and the other one... (BBC News, 5 October 2004)

Let us now address the question of how what ends up in its surface position. Based on the particular distribution of parenthetical what just outlined, we would like to suggest that it comes with a feature, call it [F-NUM], searching for a matching numeralrelated feature in a potential host clause. Once it finds a matching feature, it enters the corresponding host structure in the way outlined below.

Before we proceed, a few remarks are due on the nature of the feature inherent to what. We would like to stress that we are not dealing with a categorial selectional feature. In generative terms, any syntactic head comes with a selectional feature which determines the syntactic category of its complement. We have already established above that parenthetical what cannot function as a syntactic head taking elements of the host clause as its complement. However, we do not consider it a coincidence that the overwhelming majority of parenthetical what (95 per cent) precedes a cardinal number. Rather, we attribute this distribution to a corresponding feature inherent to what which looks for a matching feature in the host clause and which can be satisfied by matching it against this corresponding feature. Evidence for the assumption that what has a feature of this kind also comes from the fact that other one-word interpolations such as say or like are far more mobile in their syntactic distribution (cf. the examples in (20) and (21)). Their syntactic flexibility and frequency of occurrence follow straightforwardly under the assumption that, unlike what, they do not have a feature forcing them to search for a matching node, and thus for a particular position in their host structure.

(20) Like

(a) Between 2 objects in a ditransitive construction (preceding a definite Det) As soon as they got on to doing phonetics I left uh partly because it was nine o'clock in the morning and not really a very good time for me or my bank balance because it costs me like a fiver more to come in for nine o'clock than it does if I come in for eleven (ICE-GB: s1a-008, \#43)

(b) Preceding the subject (preceding a definite Det)

But like the record company then refused to pay me without having seen the pictures (ICE-GB: s1a-052, \#150)

(c) Within the verb group (preceding an Adv) I should have like just whipped up this amazing meal (ICE-GB: s1a-071, \#31)

(d) Between $P$ and its complement

I got quite good at like heating up thermometers and stuff and give myself a temperature and things (ICE-GB: s1a-076, \#92)

(e) Reported dialogue or thought (e.g. preceding a V) 
(e1) And I thought like hold on you're wearing the T-shirt (ICE-GB: s1a-068, \#089)

(e2) when my brother yells he's like, 'Do it now!' like that and I'm like, 'No!' (from Levey, 2005)

(f) Preceding predicates of various categories (preceding A in f1, Det in f2, $P$ in f3)

(f1) AP: he was like nice to all the rest (from Levey, 2005)

(f2) NP: I mean she's like the woman for him to like be with for the rest of his life sort of thing from what I can gather (ICE-GB: s1a-071, \#226)

(f3) PP: and they was like on this boat (from Levey, 2005)

(21) Say

(a) Between subject and $V$ (preceding $a V$ )

I'd be far more upset if somebody say scratched one of my records than tore one of my books (ICE-GB: s1a-013, \#189)

(b) Between $V$ and PP-adjunct (preceding a P)

... the kind of ensemble that was operating say at the the RSC in the early days in the sixties... allowed people to feel that they were actually learning something and training together (ICE-GB: s1b-050, \#82)

(c) Between $P$ and its nominal complement (preceding a definite Det)

... if say you wanted to do a course in London at say the Institute of Education or at ... King's or wherever (DCPSE: DI-A06, \#179)

(d) Between $V$ and its nominal complement (preceding a definite Det)

and if he wants to take say this one he's got to do everything in between (DCPSE: DL-B14, \#342)

(e) Between a copula and predicate (preceding an indefinite Det) because they are say a militaristic nation... (DCPSE: DL-B15, \#321)

(f) After infinitival to (preceding $a \mathrm{~V}$ )

you know you could perhaps improve the house but to say transplant her to an old people's home... (DCPSE: DL-B33, \#282)

(g) At the edge of a clause

'cause they're all forty miles apart say so it's fairly easy to try and move hostels (DCPSE: DL-B30, \#563)

(h) Between complementizer and IP

... if say you wanted to do a course in London at say the Institute of Education or at... King's or wherever (DCPSE: DI-A06, \#179)

So how exactly does the operation by which what enters the host structure work? We assume that, initially, there are two separate syntactic structures, one representing the host sentence, the other representing the parenthetical. In this way, we account for the observation that what does not take part in any syntactic processes applying in the host structure and that it is therefore syntactically independent. We further assume that the parenthetical has the feature [F-NUM] motivated above on the basis of its distribution and on the contrast with like and say. This feature looks for a matching feature in the host structure. It finds it on the numeral and, due to basic phrase structure rules, on the immediately dominating node. This means that the properties of what can be associated with the node immediately dominating the numeral in the host structure. This, we claim, is basically how linearization works. Crucially, we are not suggesting any form of syntactic integration, but merely linear constituent ordering on the surface. 
The parenthetical relates on the surface to the node dominating the number in the syntactic host structure. In this way, its feature is satisfied by matching against the corresponding feature in the host. Note again that this is a unidirectional process in the sense that it is the feature on the parenthetical that needs to get satisfied, not the feature on the host. As a result, the parenthetical appears in a linear position related to the numeral in the host clause. The feature-matching process is illustrated in (22).

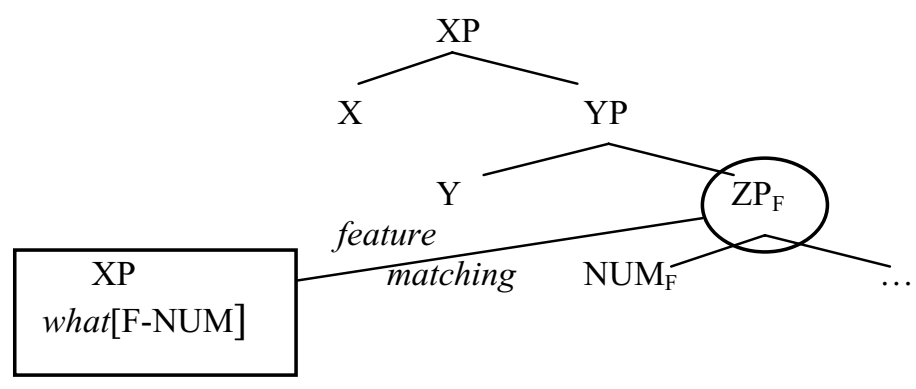

Let us now see how this approach can account for the particular distribution of what. Most importantly, it explains why what is spelled out in a position related to the node dominating the numeral. Assume for the sake of argumentation that what is attached to a node lower in the structure. In this case, its [F-NUM] feature would have to be copied up to find the matching NUM-feature, or the NUM feature inherent to the host structure would have to be copied down in order to be reached by the feature on the parenthetical. We dismiss both options. Copying the feature on the parenthetical up in the tree would mean more effort and can therefore be ruled out for economy reasons. The second option is ruled out by the very nature of the operation Merge (along the lines of Chomsky, 1995: 243), as well as by the Inclusiveness condition (Chomsky, 1995: 228). Merge holds that the object $\mathrm{K}$ formed by merging two objects $\alpha$ and $\beta$ is constituted from these two items. Inclusiveness holds that the syntactic properties of a nonterminal node are fully recoverable from the structure it dominates. A nonterminal node can therefore never contain a feature copied down in the tree.

Now imagine that what gets associated with a higher node in the tree. In this case, either the selectional feature on the parenthetical would have to be copied down to reach the matching feature inherent to the host structure or the host structure feature would have to be copied up. Both options are ruled out for the same reasons that also prohibited attachment of the parenthetical to a lower node in the tree.

This then leaves us with the original option that what gets associated with the node immediately dominating the numeral. Theoretically, it could now be spelled out in three different positions: (i) before the numeral (where it actually appears), (ii) immediately following the numeral, or (iii) following the whole constituent (here labelled ZP). Consequently, we are left with at least two open questions concerning the distribution of parenthetical what that we cannot answer along syntactic lines. The first question is: why does what have to be spelled out in the position preceding the numeral, but cannot appear in any other position related to the same node in the host 
structure? We believe that there are discourse-related reasons for this which we will address immediately. The second question is why what cannot appear in sentenceinitial position as, for instance, in (14c) above. If what precedes the numeral because of its [F-NUM] feature in combination with discourse-related factors, then it should be possible for the parenthetical to always do so regardless of where in the sentence the numeral appears. We believe that the answer to this question lies in the prosodic characteristics of what which will be discussed in section 4 below. Let us now first turn to the pragmatic features of parenthetical what.

\section{Pragmatics}

The aim of this section is to account for the speaker's preference to insert an additional element into the syntactic string of the host, and, more specifically, the motivation behind the positioning of what right in front of the numeral. Given that parenthetical what is not seen as part of the hierarchical structure of the host, it is worth investigating how this insertion relates to the rest of the utterance and if the overall utterance interpretation is altered in any way by the presence of what.

\subsection{Optimal relevance and parenthetical what}

To address these questions, we would like to base our analysis in the Relevance Theory framework (RT, as developed by Sperber \& Wilson, 1986, 1995). RT rests on the Principle of Relevance which states that '[e]very act of ostensive communication communicates a presumption of its own optimal relevance' (Sperber \& Wilson, 1995: 158). The principle offers a generalization of ostensive-inferential communication and is viewed from the point of view of the subpersonal cognitive processes (Sperber $\&$ Wilson, 1995: 162).

Optimal relevance is seen as a function of costs and effects. The hearer does not expect the speaker to provide him/her with an utterance that is unjustifiable in terms of processing cost. The achieved cognitive effects should outweigh the processing effort spent. Obeying the Principle of Relevance, the hearer expects that he/she can obtain the intended contextual effects at a minimum cost of processing. For example, the processing cost of a lengthier utterance would only be justified if the speaker has aimed to achieve more contextual effects than otherwise accessible. Undoubtedly, the insertion of an additional element of the parenthetical type increases the processing cost. In the case of parenthetical what, we argue that the speaker's choice is justifiable because by uttering what in front of the numeral, the speaker must believe that it is worthwhile for the hearer to undertake the additional processing entailed by the extra linguistic clue. At this stage, we would like to suggest that the insertion and processing of parenthetical what give rise to certain contextual assumptions that are otherwise not so strongly manifested. Inevitably, we are bound to ask ourselves what are the assumptions that what gives rise to, and how are they reached? But before we answer this question, we need to say a few words about the process of utterance interpretation. 


\subsection{Understanding utterances}

It is a widely accepted view that understanding utterances is not simply a matter of knowing the meanings of the words and the way in which they combine to form grammatical constructions. As Blakemore convincingly argues, if taken on its own, linguistic meaning does not determine the relevance of the communicated utterance (Blakemore, 2002: 59-70). Actually, the interpretation of the linguistic meaning alone fails to communicate the speaker's intended utterance: 'There is inevitably a gap between what the grammar delivers - the linguistically determined semantic representation - and the interpretation intended' (Blakemore, 2002: 64). She supports this claim by referring to slip-of-the-tongue examples where the linguistic system is overridden by the inferential system. Crucially, the overall interpretation of utterances is not constrained by the skeleton of linguistically determined semantic representations. This view is also captured in the semantic under-determinacy thesis developed by Carston (1999) and the fact that 'natural language sentences do not encode full propositions but merely schemas for the construction of (truth-evaluable) propositional form' (Carston, 1999: 105).

\subsubsection{Procedural what}

Apparently, inference plays an important role in utterance interpretation. Considering that, it is no surprise that linguistic meaning is divided into two types: conceptual and procedural (cf. Blakemore, 1987, 1991, 1992, 2002). Roughly speaking, the two types of meaning serve different purposes in interpretation. Conceptual meaning contributes to propositional representations. For example, the word table encodes the concept TABLE, the word joy encodes the concept JOY. On the other hand, there are expressions which are seen as procedures, but not concepts. Blakemore defines procedures as expressions which 'do not encode a constituent of a conceptual representation (or even indicate a concept), but guide the comprehension process...' (Blakemore, 2002: 90-1). To put things in perspective, parenthetical what does not encode the concept WHAT as table encodes TABLE. Just as, for example, pronominals do not have nominal content and are not associated with a general concept (but are a 'key' to a concept) (cf. Blakemore, 1992: 70), so is parenthetical what devoid of a specific concept. No concept is accessible for what as one is for table. Consequently, in this article, we will treat parenthetical what as a linguistic clue which encodes procedures it is present in the utterance to lead the hearer into taking an intended inferential path.

To demonstrate that what belongs to expressions which encode procedural meaning, we would like to refer to three diagnostic tests that are associated with expressions that do not encode concepts. First, when reporting an utterance with parenthetical what in it, the parenthetical is left out and cannot be included in the reported clause, cf. (23):

(23) (a) we're a fairly small group because there's only what four of us uh (DCPSE: DL-A08, \#543) 
(b) She said that they were a fairly small group because there were only (\#what) four of them. ${ }^{7}$

Second, by inserting what, the speaker does not lay herself open to charges of untruthfulness (as would be the case if she used an illocutionary adverb, for example) (cf. Ifantidou, 2001), as in (24) in response to (23a):

(24) \#No, you are wrong. There are not four, but five of us.

Finally, while concepts can combine with other concepts to form even more complex (new) concepts, expressions with procedural meaning cannot combine with other procedures to combine more complex (new) procedures, but they are merely listed, as in (25). ${ }^{8}$ We refer to this as 'inability for phrase expansion' (cf. Blakemore, 2004; Kavalova, 2004).

(25) ... because there're only like, say, what four of us. ${ }^{9}$

The fact that procedural what is determined in such a negative context (i.e. what it cannot do, rather than what it does) should not diminish its value. The existence of such 'functional' expressions is justified by the Principle of Relevance itself. If the degree of relevance increases with the number of cognitive effects and decreases with the amount of processing required, the implementation of a procedure to enhance the intended cognitive effects or lead in the direction of accessing the right set of cognitive assumptions is consistent with the speaker's aim at optimal relevance. In the RT framework, it is the sole responsibility of the speaker to ensure successful communication and interpretation of his/her intended proposition. To this end, the speaker must account and compensate for any potential constraints on the processing abilities of the hearer (as well as his/her own).

\subsubsection{What and focus}

It is in the speaker's interest that the hearer recognise an utterance as worth processing and consequently invest effort in the derivation of assumptions and effects. To achieve this, sometimes the speaker may choose linguistically to encode a signal to alert the hearer to something and to indicate how to interpret it inferentially.

Based on our dataset, we would like to argue that parenthetical what tends to precede the focus of an utterance. This is particularly clear in examples such as the ones in (26), where what is preceded by the focus particle only (cf., e.g., König, 1991; Rooth, 1996 on focus particles). In (26a), the numeral also precedes the predicate in an existentialthere construction. Note that it has been argued in previous research that constructions

${ }^{7}$ Note that if what is inserted in the utterance, then it'll be attributed to the speaker (reporter) of (23a), but not to the person whose speech is being reported.

8 Blakemore (2004: 231) comments that although more than one procedural expression can occur in an utterance, it is not clear whether they can combine to express one complex procedure. Instead, they sustain their individual constraints.

${ }^{9}$ Notice that what remains the expression nearest to the numeral in the utterance. This can be attributed to its inherent feature, but we will also argue that this position is related to its pragmatic function with respect to focus (see below). 
of this kind can be used to place a hearer-new, and thus focused, constituent in final position (e.g., Birner \& Ward, 1998: 102-6; Ward \& Birner, 1995). We consider four of us in (26a) and six months in (26b) to be the focus of the utterance.

(26) (a) We're a fairly small group because there's only what four of us (DCPSE: DL-A08, \#546)

(b) ... because it's only what six months since your brother died... (DCPSE: DLD08, \#129)

We suggest that parenthetical what is implemented by the speaker to assist the hearer in recognizing and quickly accessing the material in the focus of the utterance. Even though the focus material may already be marked by a focus particle or be placed in a marked sentence structure (e.g. an existential-there construction), the speaker recognizing his/her responsibility to convey his/her thoughts in the most faithful waychooses to implement an additional linguistic clue.

Based on the assumption that utterance processing is subordinated to temporal sequencing (cf. Sperber \& Wilson, 1995: 202-6), e.g. due to the nature of speech organization - certain concepts/procedures are bound to become available before others - we argue that the speaker chooses to insert what in his/her utterance to mark the focus structure as such and to explicitly draw the hearer's attention to the numeral that follows. Thus an even more faithful representation of the speaker's thoughts is achieved and the hearer is led straightforwardly in the direction of how to interpret the numeral. We suggest that this, in turn, explains the preferred position of parenthetical what: it almost always occurs in front of a numeral (which is either the focus or part of a focused constituent). The first of the two open questions formulated at the end of section 2 - 'Why does what have to be spelled out in the position preceding the numeral ...?' - can thus be answered along these lines.

While the procedural character of parenthetical what accounts for its preferred place of interpolation and ensures that a particular utterance structure is 'focused up', we believe that its functions do not cease here. The insertion of what seems to determine the final interpretation of the utterance. We will address this in the next section.

\subsection{Style and constraints on interpretation}

In pursuit of relevance, the speaker chooses his/her style. The speaker's beliefs and assumptions about the hearer's cognitive and processing abilities and contextual resources determine what the speaker chooses to make explicit and what he/she withholds and leaves implicit (cf. Sperber \& Wilson, 1995: 218-24). Based on this, RT distinguishes two types of communicated assumptions, namely explicated and implicated. In the context of what, it is important to see whether the constraints introduced by the insertion of the parenthetical are targeted at what is explicated or what is implicated by the speaker.

The following examples demonstrate that what the speaker communicates with what does not belong to the explicit content, but ensures that certain information is 
conveyed implicitly. The interpretation of the host is constrained at the implicit level. The speaker reorients the hearer to a set of assumptions, which influences the final utterance interpretation. Thus, parenthetical what offers constraints on implicatures. ${ }^{10}$ In (27), the speaker's intention is to imply that there are not enough people working on the project. This is also enforced by the second part of the utterance in (27) where the speaker suggests inviting an additional person, Sabina, to join the team.

(27) A: we're a fairly small group because there's only what four of us.

A: thought it would be nice to invite Sabina uhm cause she and I share number of cases ... (DCPSE: DL-A08, \#546-7)

In (28), the speaker emphasizes that the Prime Minister has waited for many years to pass the ban on hunting.

(28) The PM has tried to pass this law for over what 7 years now (BBC News, 17 February 2005)

Based on the examples in our dataset, we conclude that the insertion of what specifies the interpretation and makes the speaker's intentions more explicit. More specifically, we suggest that by implementing what the speaker makes accessible certain contextual assumptions along the lines that something (typically, the topic of the utterance) is perceived as either being too little/few (cf. (27)) or too much/many (cf. (28)). ${ }^{11}$ By following the inferential path guaranteed by what, the hearer is led to derive certain contextual assumptions that would otherwise be less accessible. For example, in the case of (27) the clear implication is that the team needs to attract more people, i.e. there are too few at the moment. What is implicitly conveyed in (29) is the speaker's irritation that he has had to wait for such a long time in front of the hairdresser's, i.e. too much. ${ }^{12}$

(29) She's been in there for what just over 2 hours now. (Trouble in the store, BBC1, 2 Aug 2005)

If the utterance was devoid of the inserted parenthetical, then we could argue that the hearer could not directly activate the intended inferential route and would not be able to quickly and efficiently constrain the recovery of the proposition. In (30a), where what is included in the utterance, the hearer immediately accesses the set of assumptions that has been presented to him by the additional clue, namely that 2 per cent is 'too

10 Blakemore (1992: 81) defines implicatures as 'assumptions derived from the proposition that the hearer takes the speaker to have expressed together with the context'.

11 It is not unusual for inserted elements to convey ideas of this type, thus adding some interpretation adjustments to the discourse. For example, Shiffrin (2003) explains that $o h$ displays information as 'new' or 'unexpected' (it could be seen as being too much/too little) to a recipient (Shiffrin, 2003: 58). The possible links between parenthetical what and the interjection $o h$ when preceding a numeral, as in 'It must have saved me $o h$ thirty seconds' (Dispatches: Supermarket secrets, Channel 4, 1 Aug 2005), are also worth investigating. In this observed example, the speaker emphasizes that buying a prepacked salad hasn't helped her save time, i.e., it has saved her too little time, but at the same time has cost her too much.

12 It is curious to note that this utterance (observed) was accompanied by a nonlinguistic clue. The speaker looked at his watch while producing the utterance. 
little'. However, in the case of (30b), if we remove what, the hearer will not be able to directly access the implication that 2 per cent of the employment in the EU is too small a fraction for which to expect funding that amounts to 40 per cent of the overall EU budget.

(30) (a) ... but what I have an objection to is the European Union deciding collectively that it is going to put 40 per cent of its budget into an area where you have got what 2 per cent of the employment. (Tony Blair on farming subsidies in the EU, Channel 4 News, Channel 4, 14 June 2005)

(b) ... but what I have an objection to is the European Union deciding collectively that it is going to put 40 per cent of its budget into an area where you have got 2 per cent of the employment.

Crucially, then, the presence of what takes the utterance interpretation to an inference route otherwise not so straightforwardly accessible.

Undoubtedly, the implementation of parenthetical what contributes to the dynamics of interaction. It gives an important cue in the ongoing interaction. All our recorded examples come from spoken material and are either from dialogues or monologues with a clear audience in mind. But despite being interactional, parenthetical what is not interpreted as a turn-taking device. On the contrary, by inserting what, the speaker does not forfeit the right to continue with his/her intended utterance. Even though parenthetical what is usually followed by a pause (cf. section 4.2), it is perceived as a floor-holding device. That the speaker does not really expect an answer, correction, interruption or the like from the hearer becomes clear from the example in (31). Here both speaker and hearer comply with the implications conveyed by the insertion of what in the string of utterance: the speaker continues with her utterance after the implementation of what, and the hearers do not interrupt her.

(31) A: we're a fairly small group because there's only what four of us uh A: thought it would be nice to invite Sabina uhm because she and I share number of cases and also so that it wasn't just uh monopolized by social workers uhm and feeling that eventually it would be nice if we could include the senior nurse uh if he or she was sort of fairly interested in family work in the group as well coz you know if you can have a few more people I think it's easier $\mathrm{C}: \mathrm{hm}$ $\mathrm{N}$ : yes I think so too (DCPSE: DL-A08, \#546-551).

We argue that it is this floor-holding function of parenthetical what that occasionally gives the impression of what being used to mark hesitation. Floor-holding devices are often perceived as a delaying tactic which can consequently evoke a feeling of hesitation (cf. Brinton, 1996: 37). This perceived hesitation should not be confused with the speaker's feeling uncertain about what to say. It is clear from our examples (and the contexts in which they occur) that the speaker is often well aware of the number he/she intends to relate. The speaker does not expect a correction, nor does the hearer offer one. 
This is in line with our suggestion that parenthetical what, unlike some of its homonymous relatives, has lost its interrogative meaning. That the speaker has a clear understanding and differentiates between parenthetical what and interrogatives is illustrated in the dialogue in (32). Here the speaker utilizes what in her first utterance, with all its discussed features and functions present, whereas in her next utterance she is no longer sure of the number she mentions and consequently she requests confirmation of the number of years they have been married for, employing the Q-word how long rather than what. It is only under these circumstances that the hearer picks up this utterance as a question towards her and volunteers an answer.

(32) A: so getting in touch with real feelings is obviously something that is extremely difficult for you to do but I believe that if at this stage - and it isn't too late because it's only what six months since your brother died - I believe that if you can bear to begin to really get in touch with those real feelings of pain and fear and anguish that you can in that way begin at that point to be able to make real contact with your wife if she is understanding enough to be able to accept you Obviously I think what's happened in the past I mean you've been married for how long fifteen years

B: twenty-two years

A: twenty-two years

(DCPSE: DL-D08, \#127-131)

At this stage, it is important to note that sometimes the speaker, having included what in his/her utterance, may be interrupted or followed by the hearer, but only with a back-channel cue, similar to what has been described as a comment of agreement or simply expression of attentiveness, e.g. $\mathrm{mhm}$, yeah, or a nod (cf. Verschueren, 1999: 38). In dialogues this is quite often the case, as can be seen quite clearly in example (31) above and in the following example: ${ }^{13}$

(33) A: and there's usually what three bedrooms

C: yeah which means that each kid has got two children to <unclear syllable> (DCPSE: DL-B33, \#644-5)

Thus far, we have employed the syntactic and pragmatic features of parenthetical what to account for its observed behaviour. We have argued that it owes its position in the same projection as the numeral to the [F-NUM] feature that is part of its morphosyntactic representation. We have also seen that while this feature and our corresponding syntactic approach cannot explain the preference of parenthetical what for the position immediately preceding the numeral, this can be accounted for along the lines of its pragmatic functions, in particular by the fact that it 'focuses up' the numeral and thus contributes to the elicitation of more cognitive effects. However, at this point we are not yet in a position to explain why what cannot occur in sentenceor clause-initial position, even if in front of a numeral. We will offer an answer to this question in the next section.

13 In this dialogue, the exact number of bedrooms has already been mentioned (about seven lines before). In the case of (33), we take C's response as a sign of attentiveness. 


\section{Prosody}

While the syntax of what explains its position of being attached to the projection of which the numeral is a part, and its pragmatic characteristics account for the fact that it has to precede the numeral, it is its prosodic properties, in particular the way it affects the prosodic phrase structure of its host, that explain why it cannot occur in sentence- or clause-initial position. Before we turn to these issues, we discuss some aspects of prosodic theory and the syntax-phonology mapping that play a role in the argumentation.

\subsection{Background}

Following the theory of prosodic phonology (Nespor \& Vogel, 1986; Selkirk, 1986, 1995; Truckenbrodt, 1995 and related work), we assume the prosodic hierarchy and its relation to syntactic constituents given in (34).

(34) Prosodic hierarchy Prosodic Utterance Intonational Phrase Phonological Phrase Prosodic Word

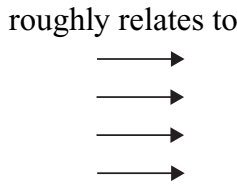

Syntax

Utterance

Root Clause

Lexical XP

Morphosyntactic Word

With respect to the mapping of syntactic onto prosodic constituents, we essentially assume an end-based account, as developed in Selkirk (1986, and subsequent and related work). Crucially (and sufficiently here), this account predicts that in English, the right edge of a syntactic phrase coincides with the right edge of a Phonological Phrase.

\section{(35) XP-alignment}

The right edge of any XP in syntactic structure coincides with the right edge of a Phonological Phrase.

For illustration, consider the example in (36). The relevant fragment of the example is given in (36a), while the syntactic structure is specified in (36b) as relevant. Following $\mathrm{XP}$-alignment as given in (35), the syntactic structure is mapped onto the prosodic structure given in (36c), such that there is a Phonological Phrase boundary at every syntactic phrase edge, i.e. after the subject and after the first segment of the VP (cf. Gee \& Grosjean, 1983 and Truckenbrodt, 1995: 53ff., 84ff., 1999: 235 for the difference between syntactic adjuncts and complements in prosodic theory). This results in a prosodic structure where the subject, the VP1 consisting of verb and complement, and the PP-adjunct are all mapped onto separate Phonological Phrases. (Here and below, phrasal prosodic boundaries are indicated by round brackets.) Crucially, according to XP-alignment, there is no prosodic boundary above word level between a syntactic head and its complement.

(36) There is no unless, 'cause no one has said whoopsy daisies for what fifty years, and even then, it was just little girls ... (=(5b))

(a) No one has said whoopsy daisies for what fifty years 
(b) syntactic structure (as relevant)

$[\text { No one }]_{\mathrm{NP}}\left[[\text { said whoopsy daisies }]_{\mathrm{VP} 1}[\text { for fifty years }]_{\mathrm{PP}}\right]_{\mathrm{VP} 2}$

(c) syntax-phonology mapping/prosodic phrasing

(no one) (said whoopsy daisies) (for fifty years)

The Strict Layer Hypothesis (SLH; Selkirk, 1984), informally phrased in (37), dictates that a prosodic domain at any level in the hierarchy must be dominated by a unit of the next higher level. It follows from this that unlike in syntax there can be no embedded or recursive structures in prosody. ${ }^{14}$

(37) Strict Layer Hypothesis (SLH)

A unit at any given level in the prosodic hierarchy can never be composed of anything other than units at the next lower level.

A note on terminology: we will use the terms Intonational Phrase and Phonological Phrase to refer to specific levels in the hierarchy as given in (34) above. For both levels, we will also make use of the more general terms prosodic domains or phrasal prosodic domains whenever more specific terminology is unnecessary. Furthermore, we occasionally employ the terms tone group and intonation group as used in previous literature. For the present analysis, nothing hinges on the question of whether the relevant constituents are equivalent to Intonational Phrases or Phonological Phrases. In any case, the terms refer to phrasal prosodic constituents.

\subsection{Prosodic characteristics of parenthetical what}

In general, many prosodic properties that have been described for other types of parentheticals (e.g. Bolinger, 1989: 185-203; Taglicht, 1998, and Wichmann, 2001: 93-9 for English; Fagyal, 2002 for French) are also typical of parenthetical what. It is very clear, for example, that what, like other parentheticals, interrupts the prosodic flow of its host utterance in that it is set off from the rest of the utterance by pauses. Two general patterns, illustrated in figure 1, can be observed. In (a), the parenthetical is set off from the following material by a pause, but there is no pause preceding what. In (b), on the other hand, what is preceded and followed by a pause. We will return to this issue below in connection with prosodic phrasing.

Another general property of parenthetical what is that it is always realized on a low pitch level, or with falling pitch, where the pitch fall is often from a low to an even lower level, often to or below the base line of the rest of the utterance. If it is falling, it can either continue the pitch fall started on the preceding material, or there can be a distinct pitch fall on the parenthetical alone. The pitch pattern on what seems to be related to the occurrence of the surrounding pauses in the following way. If there is

14 In more recent literature, the SLH has been argued to be made up of more primitive constraints. LAYEREDNESS (No prosodic constituent $\mathrm{C}^{\mathrm{i}}$ dominates a prosodic constituent $\mathrm{C}^{\mathrm{j}}, \mathrm{j}>\mathrm{i}$ ) and HeADEDNESS (Any $\mathrm{C}^{\mathrm{i}}$ must dominate a $\mathrm{C}^{\mathrm{i}-1}$ ) constitute the essence of the SLH. They are complemented by Exhaustivity (No $\mathrm{C}^{\mathrm{i}}$ immediately dominates a constituent $C^{j}, j<i-1$ ) and Nonrecursivity (No $C^{i}$ dominates $\left.C^{j}, j=i\right)$; cf. Selkirk, 1996: $189 f$ and references given there. For the present study, it suffices to refer to the SLH. 
(a)

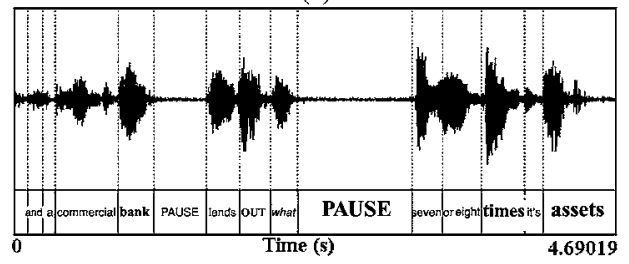

[and a commercial bank lends out what seven or eight times its assets], on the principle that everybody doesn't call for their money on the same day (DCPSE: DL-E04, \#79)

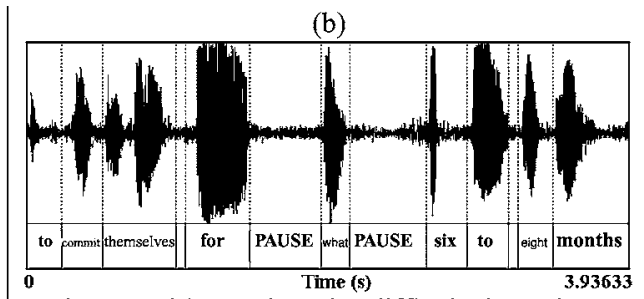

... because it's surely quite difficult these days to persuade an actor or actress [to commit themselves for what six to eight months] ... (ICE-GB: s1b-050 \#72)

Figure 1 What set off by pauses

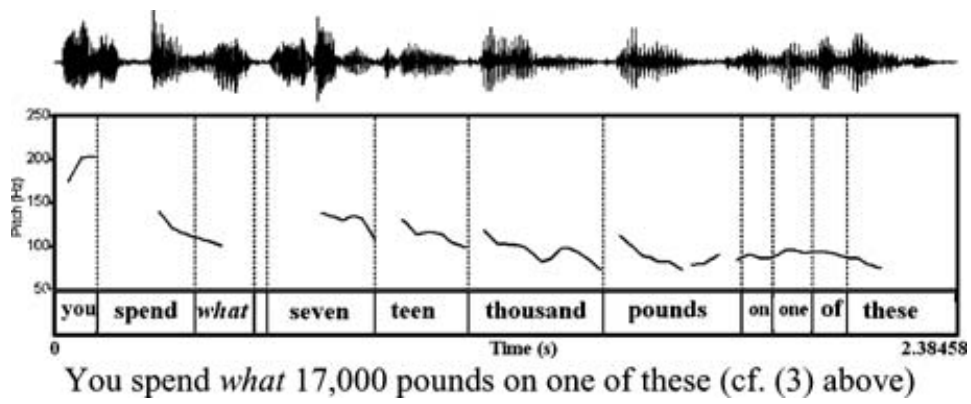

Figure 2 Pitch fall on what continued from previous material (no preceding pause)

no pause before what, the falling pitch contour that starts on the preceding material is usually continued on the parenthetical. This is the case in the example represented in figure 2, where a continuous pitch fall can be seen on the sequence You spend what. If what is surrounded, rather than only followed, by pauses, the parenthetical can be realized at a very low level without involving a pitch fall (cf. figure 3a), or there can be a distinct pitch fall on what (cf. figure 3b). As opposed to longer parentheticals, what never has a rising terminal. It is also worth noting that sometimes parenthetical what is very weak and barely audible.

At this stage, recall from section 2 above that the parenthetical and its host are structurally independent and linked only by a process of feature matching. We will argue in what follows that there is also evidence for separate prosodic structures which are then linked to yield the surface representation.

It has been argued in previous studies on the prosodic characteristics of parentheticals that the gradual pitch declination of the matrix clause is essentially the same, whether it is uttered with the parenthetical or as a complete utterance by itself. Cooper \& Sorensen (1981: 72ff.) compare sentence pairs such as the one given in (38).

(38) (a) The book on the table was a gift from my mother.

(b) The book on the table, it seems to me, was a gift from my mother. 


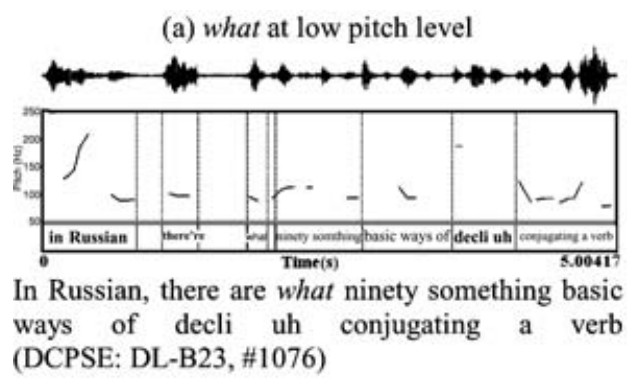

Figure 3 Pitch on what preceded by a pause

Pitch values were measured for all underlined syllables. Crucially, the peak F0 values within the parentheticals are much lower than within the rest of the utterance, and pitch levels are resumed after the parenthetical at the point at which they were interrupted. The parenthetical was not integrated in the overall downward trend. Furthermore, comparing sentences of type (38a) with those of type (38b), the points measured for the matrix clause did not essentially differ whether or not interrupted by a parenthetical. Cooper \& Sorensen conclude that parentheticals do not disrupt the overall prosodic structure of the utterance, but that they have their own declination domains instead.

In an attempt to define parentheticals prosodically, Wichmann (2000: 99) states that her examples from the Spoken English Corpus (SEC; cf. Wichmann, 2000: 3 for references) all have in common that 'if they were deleted they would leave the rest of the utterance prosodically coherent'. Let us now take a look at the behaviour of what in this respect.

(39) (because) it's surely quite difficult these days to persuade an actor or actress to commit themselves for what six to eight months when there is always the possibility isn't there of lucrative television work (ICE-GB: s1b-050, \#72)

Consider the example in (39). The corresponding sound file was taken from the corpus and the parenthetical was edited out. The resulting manipulated utterance sounded essentially normal, as if what had never been in it. The written sentence was then presented to a female native speaker of English in two versions. One version contained what exactly as in (39) above, the other one came without the parenthetical. The speaker knew which kind of what was involved. She was instructed to read the sentences in a normal, colloquial way. The target sentences were preceded, followed, and separated by a number of filler sentences. We digitized the recording into individual sound files and the intonation contours of both target sentences were analysed, along with a third version which was the sentence originally containing what, but with what having been edited out. For all sentences, the declination was essentially the same, i.e. the parenthetical what did not affect the overall declination of the utterance. Figure 4 compares the utterance made without the parenthetical (panel (a)) with the utterance where parenthetical what was edited out (panel (b)). They look the same except for the 
(a)

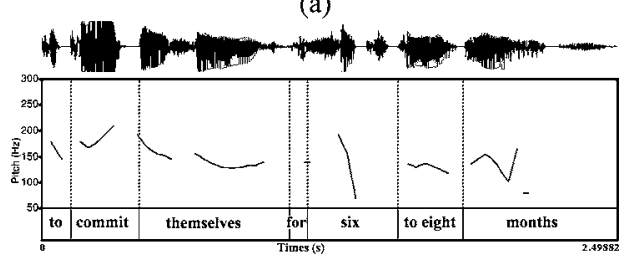

[to commit themselves for six to eight months] (b)

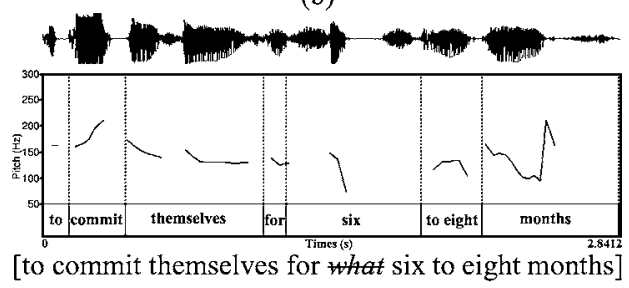

Figure 4 Sentence declination

length of the numeral six which was longer where preceded by the parenthetical. ${ }^{15}$ Our little pilot study therefore suggests that what, just like other parentheticals, does not affect the overall declination of the utterance in which it occurs.

Given this evidence from the overall pitch declination within a sentence, it seems reasonable to assume that just as in syntax, there are two separate prosodic representations, i.e. the prosodic representation of the host structure and that of the parenthetical. Despite the parenthetical being linearly integrated in the host structure, at least certain prosodic characteristics of the host remain unaffected. For illustration of the resulting prosodic representation, consider the example in (40) and its hierarchical structure in (41). Let us ignore parenthetical what for a moment and consider only the syntactic structure of the host (cf. (40b)) and its mapping onto prosodic structure according to XP-alignment given in (40c). Crucially, the PP for fifty years forms one Phonological Phrase. Parenthetical what comes with a prosodic structure of its own and gets accommodated in the prosodic structure of the host at surface level in a way to be specified below. (Here and in following examples ' $L$ ' stands for 'level in the prosodic hierarchy'.)

(40) (a) No one has said whoopsy daisies for what fifty years

(b) syntactic structure (as relevant)

[No one] [ $\left.[\text { has said whoopsy daisies }]_{\mathrm{VP}}[\text { for fifty years }]_{\mathrm{PP}}\right]_{\mathrm{VP}}$

(c) syntax-phonology mapping/prosodic phrasing

(no one) (said whoopsy daisies) (for fifty years)

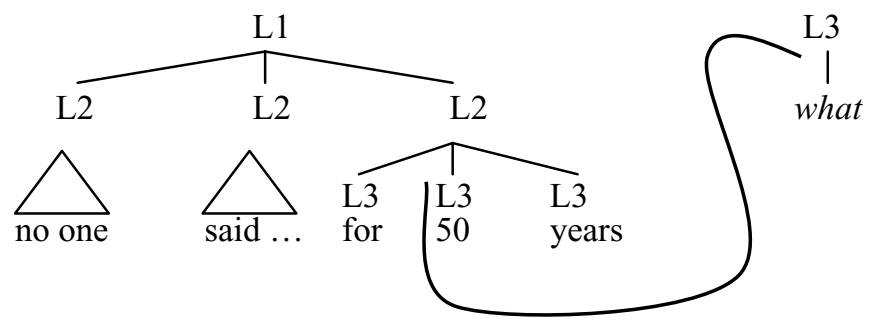

15 Note that this lengthening could be interpreted as being indicative of a high degree of emphasis on the numeral, which would go hand in hand with our assumption that parenthetical what in general serves to emphasize the following numeral and/or the NP it is part of (cf. section 3 above). However, since we only tested one example with one speaker at this stage, it is not safe to draw any conclusions in this direction. 
(a) (cf. (42a))

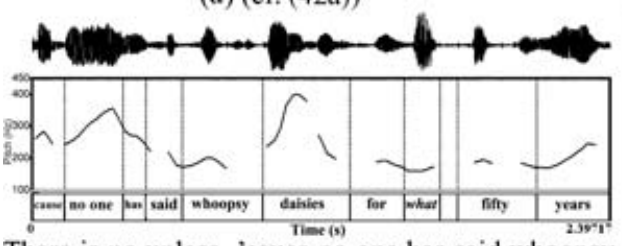

There is no unless, 'cause no one has said whoopsy daisies for what fifty years [...]

predicted: said whoopsy daisies) (for fifty years) actual: said whoopsy daisies) (for what) (fifty years)

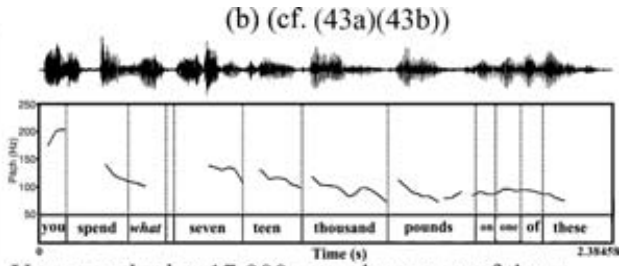

You spend what 17,000 pounds on one of these predicted: spend 17,000 pounds) (on one of these) actual: spend what)(17,000 pounds) (on ...)

Figure 5 Intonation contours (cf. examples (42) through (44))

Assuming two independent prosodic structures, however, cannot be the end of the story. Just as parentheticals are linearly integrated in the syntactic structure of their host by a process of feature matching and are thus structurally not completely unrelated to the host, what (like other parentheticals) does affect the prosodic structure of the host utterance in some way and it enters into a prosodic relationship with its host at some level. We have already seen above that what can be either followed or surrounded by pauses. If we take pauses as evidence for prosodic boundaries, it seems that parenthetical what, due to its distribution, introduces a rather strong prosodic boundary in a position where there would be no boundary otherwise, e.g. between a head and its complement. Consider the examples in (42) through (44). Example (42) is repeated from (40). The parenthetical occurs between the prepositional head for and its complement fifty years. As mentioned above, the PP for fifty years is mapped onto a single Phonological Phrase according to prosodic theory. However, what not only occurs between head and complement, it is also followed by a pause (cf. figure 4a)). If we take this pause as evidence for the presence of a prosodic boundary, we have to assume a boundary between what and fifty years, i.e. in the middle of the PP, resulting in the prosodic phrasing given in (42c).

(42) (a) no one has said whoopsy daisies for what fifty years.

(b) ... said whoopsy daisies)(for fifty years)

(c) ... said whoopsy daisies)(for what)(fifty years)

The example in (43) behaves correspondingly, but this time, a verbal head and its complement are involved. According to prosodic theory, the verb spend and its complement are mapped onto a single Phonological Phrase, as shown in (43b). Due to the presence of the parenthetical between the verb and its complement, along with a following pause (cf. figure 5b)), a boundary is introduced in the relevant position (cf. (43c)).

(43) (a) You spend what 17,000 pounds on one of these.

(b) ... spend 17,000 pounds)(on one of these)

(c) ... spend what)(17,000 pounds)(on one of these) 
In (44), repeated from figure $1 \mathrm{~b}$ above, the parenthetical again separates a preposition and its complement, but this time it is surrounded by pauses which, taken as evidence for prosodic boundaries, would suggest a prosodic structure as in (44c), where the parenthetical forms a separate phrasal prosodic domain.

(44) (a) ... to commit themselves for what six to eight months.

(b) ... commit themselves) (for six to eight months)

(c) ... commit themselves) (for) (what) (six to eight months)

Crucially then, we get the patterns indicated in (45) and (46), where (a) represents the syntactic structure, (b) represents the output of the mapping of syntactic structure onto phonological structure without the presence of a parenthetical, and (c) represents the structure with parenthetical what, with '\#' indicating pauses. It seems, then, that a lexical phrase which according to prosodic theory would be mapped onto a single Phonological Phrase may, due to the presence of what, not form a single phrase. Parenthetical what thus interrupts a prosodic domain. We would therefore like to point out that while from the point of view of declination it is true that the presence of a parenthetical does not affect the prosodic structure of the host, it does affect the prosodic phrasing of an utterance, just as in syntax the linear ordering of constituents is affected.

(45) (a) $\ldots[\mathrm{X} \text { YP }]_{\mathrm{XP}}$

(b) $(\ldots)(\ldots \ldots \ldots)$

(c) $(\ldots)(\ldots$ what \#...)

(46) (a) $\ldots[\mathrm{X} \text { YP }]_{\mathrm{XP}}$

(b) $(\ldots)(\ldots \ldots \ldots)$

(c) $(\ldots)(\ldots \#$ what \#...)

In what follows, we will show that although there can be pauses before and after what, what always joins the preceding material to form one prosodic domain, i.e. the resulting prosodic surface structure is as in (47a), but crucially never as in (47b).

(47) (a) (...)(..what)(..)

(b) $*(\ldots)(\ldots)($ what $)(\ldots)$

Let us first take a closer look at (45), illustrated here by example (42) ((43) behaves correspondingly). Remember that we argued for two separate prosodic structures to start with: the structure of the host and that of the parenthetical (cf. (41) above). Since on the surface the two structures are not completely independent - the parenthetical occurs in the middle of the sentence and it affects prosodic phrasing - they are to be linked in such a way that what gets accommodated in the prosodic surface structure of the host. Assume for the sake of argumentation that in the phonological component, the structure given in (48) is generated. The assumption that the pause after the parenthetical triggers a prosodic boundary is accounted for by mapping what together with the preceding syntactic head onto one prosodic domain, while the complement (fifty years in (42)) is mapped onto another prosodic domain. Here, the prosodic hierarchy formalized in the SLH (cf. (37) above) is respected. However, under this assumption, there is no way 
in which this structure can account for the prosodic constituency of the prepositional phrase which follows from the syntax-phonology mapping. The string that forms the PP in syntax (for fifty years) fails to be a constituent at any level in the prosodic structure. We therefore reject this option.

(48) (no one)(has said whoopsy daisies)(for what)(fifty years)

Instead, we would like to pursue another way of accommodating what in the prosodic surface structure and borrow Ladd's $(1986,1996)$ idea of limited recursion in prosodic structure. Ladd suggests that the SLH can be weakened such that a structure resembling a compound in morphosyntax is allowed in prosody. He calls this structure the Compound Prosodic Domain (CPD), a definition of which is given in (49). ${ }^{16}$

(49) (a) Compound Prosodic Domain (CPD; Ladd, 1996: 244)

$\mathrm{A} C \mathrm{CPD}$ is a prosodic domain of a given type $\mathrm{X}$ whose immediate constituents are themselves of type $\mathrm{X}$.

(b)

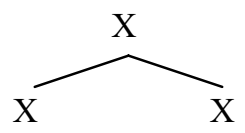

If we assume that at one stage in the mapping process the syntactic phrase, e.g. the PP for fifty years, forms a prosodic domain, and that the internal phonological structure of that domain can then be derived independently to accommodate additional material such as parentheticals linked to the host structure, we arrive at the structure in (50). Crucially, the PP is first mapped onto one Phonological Phrase. Only after the abstract prosodic structure has been formed does the initially independent structure of the parenthetical get accommodated. In order to do so, recursion along the lines of Ladd's CPD is allowed for. The prosodic constituent in question has an internal structure such that it dominates two prosodic domains of the same level. This approach accounts nicely for the prosodic constituency of the syntactic XP (here: PP), but at the same time it accounts for the boundary introduced by the parenthetical. Crucially, the strict prosodic hierarchy is still respected at the abstract level of the output of syntax-phonology mapping, and the SLH is partly dispensed with only to accommodate the parenthetical.

(50) (no one)(has said whoopsy daisies)((for what)(fifty years))

Let us now move on to the structure in (46) which seems to imply that due to preceding and following pauses (cf. (44)), the parenthetical might form a phrasal prosodic domain of its own.

16 Under the assumption of LaYeredness, Headedness, Exhaustivity, and NonReCursivity replacing the SLH (cf. footnote 14), it is HEADEDNESS and NonRECURSIVITY that are violated in compound prosodic configurations. That some recursion has to be allowed for in prosodic structure has also been argued elsewhere in the relevant literature. Truckenbrodt (1995: 72-6), for instance, based on data from the Bantu language Kimatuumbi, argues for recursive prosodic structures at the Phonological Phrase level. Cf. also Zec \& Inkelas (1990) and Zec (2005) for clitics in recursive prosodic structures. 
At the abstract level of the syntax-phonology mapping output, the prosodic representation respecting the SLH is as in (51).

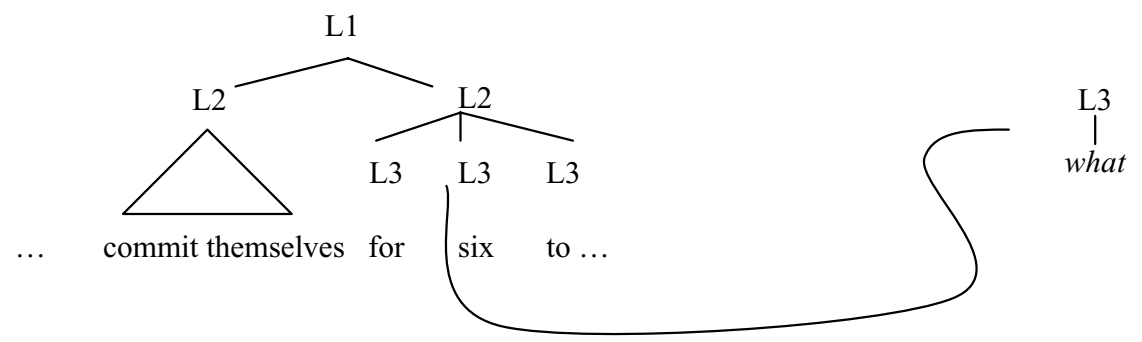

The question then is: how does what get accommodated in the prosodic surface structure? Let us assume for the moment that what forms a prosodic domain of its own, as has been argued for other parentheticals (e.g. Bing, 1985). Such a constituent would, as Wichmann (2001: 185) notes, be anomalous, because it would represent a prosodic unit at phrase level which may come without a pitch accent or pitch movement and can be very weak prosodically (cf., e.g., the example in figure 3a).

Another way of looking at these matters, one we will adopt, is to assume that parentheticals do not necessarily form a prosodic domain of their own. Pauses do often serve as a cue to prosodic boundaries between domains. They are, however, not a sufficient criterion, nor a reliable one. Among other criteria that mark phrasal boundaries is the pitch of unaccented syllables. This is because changes in pitch level and direction most frequently occur on accented syllables. If a pitch change occurs on unaccented syllables, it can be taken as an indicator of an intonation group boundary. Specifically, after falling tones followed by low unaccented syllables there will be a slight step-up to the pitch level of the unaccented syllables at the beginning of a new intonation group. This reflects the fact that low unaccented syllables at the beginning of an intonation group are generally at a higher level than low unaccented syllables at the end of an intonation group (cf. Cruttenden, 1997 for discussion).

Looking at what, it becomes obvious that it is always followed by a step-up in pitch. The low pitch level on the parenthetical is never continued on the following word. The reader can easily verify this point by looking at the F0 tracks given above (e.g. in figures 2, 3 and 5). We therefore assume that what joins the preceding prosodic domain, even if preceded by a pause, but that it is always followed by a phrasal boundary. ${ }^{17}$ Let us now return to examples (44) and (51) and the corresponding prosodic surface structure. Under the assumption that what joins the preceding material to form a prosodic phrase regardless of a preceding pause, we are essentially left with the same structure that

17 The pause preceding the parenthetical can best be interpreted as a hesitation pause, serving a pragmatic function as outlined in section 3 above. Note also that we do not, as one reviewer suggests, consider the parenthetical a postclitic. One reason is that a clitic is by definition phonologically weak and cannot be stressed, whereas what (along with other parentheticals) can be weak, but does not have to be. The examples plotted in figures $3 \mathrm{~b}$ and 5 above represent cases where the parenthetical is in fact rather strong phonologically. 
was suggested for examples without pauses preceding what given in (50) above. The prosodic surface structure of the example in (44) is shown in (52).

(52) (... commit themselves)((for what)(six to eight months))

We conclude that what always joins the preceding material to form a prosodic domain, regardless of whether or not it is preceded by a pause. This, then, is the answer to the remaining open question we were left with before. Remember that our discussion of the syntactic and prosodic properties of parenthetical what did not leave us in a position to explain why what cannot occur sentence-initially as in (14c), repeated here as (53).

(53) * What ten novels of suspense he wrote before he went to law school.

The answer to this question follows straightforwardly from the prosodic characteristics of parenthetical what. We have shown that what joins preceding material to form a prosodic domain. If what occurs clause-initially, it is clearly impossible for it to join any preceding phonological material to form a phrase. At the same time, due to its phonological properties outlined above, it cannot form a prosodic domain of its own. A structure with what in initial position is therefore always prosodically ill-formed. ${ }^{18}$

On a more general note, it seems that the behaviour of what supports the idea of limited recursion in prosodic structure, as put forward by Ladd $(1986,1996)$. This is by no means surprising because part of the evidence for this analysis originally came from parentheticals. In his 1986 article, Ladd refers to Cooper \& Sorensen's (1981) study which showed that if a parenthetical is taken out of a given host structure, the declination of the matrix clause is essentially the same as that of a clause without a parenthetical (cf. the discussion of example (38) above). The relevant example is repeated in $(54 a)$.

(54) (a) The book on the table, it seems to me, was a gift from my mother.

(b) (The book on the table) (it seems to me) (was a gift from my mother)

(c) (The book on the table (it seems to me) was a gift from my mother)

Ladd (1986) argues that the fact that parentheticals do not seem to affect the overall declination of the utterance makes sense if we take the matrix clause as one single phonological domain instead of assuming the phrasing indicated in (54b). Specifically, he suggests that the matrix clause forms a domain across which declination applies, regardless of whether or not it is interrupted by another domain. This leads him to suggest the structure in $(54 \mathrm{c})$, where the whole sentence forms one prosodic domain, with the parenthetical embedded in the structure as another prosodic domain of the same level in the hierarchy. Ladd (1996: ch. 6.3) then develops this idea further and suggests the CPD analysis.

18 Remember that in the particular fronting example in (14), what cannot move along with the fronted numeral, nor can it stay behind. While the first option is prosodically ill-formed, the second is ungrammatical because fronting of the complement leaves no node for the parenthetical in the relevant linear position to attach to. 
Crucially in our analysis, we employ Ladd's CPD to derive a prosodic surface structure from an abstract prosodic structure which is the output of the syntax-phonology mapping process. While the abstract representation respects the strict prosodic hierarchy imposed by the SLH, this hierarchy is weakened to accommodate additional phonological material into the structure and derive the surface representation.

Before concluding, let us briefly mention a couple of points concerning the relation between the syntactic and prosodic structures. We have shown that the prosodic structure is similar to the syntactic structure in that the host and the parenthetical are represented by separate structures which are then linked to each other. In the syntax, linearization is achieved via feature-matching, while in prosody, the parenthetical gets accommodated in the prosodic surface structure in that it joins the preceding prosodic domain and triggers CPD formation. It also follows from our discussion that prosodic and syntactic structures differ in that in the syntactic as well as in the pragmatic analysis, the parenthetical groups to the right, whereas in prosody, it groups to the left. Note that as far as prosody is concerned, this is in line with Taglicht's (1998: 196) more general observation concerning the role of parentheticals in intonational phrasing according to which parentheticals may group to the left but not to the right.

\section{Final remarks}

We have shown in the preceding sections that only by looking at the syntactic, pragmatic, and prosodic properties of parenthetical what can we comprehensively account for its distribution. We fully accept that parentheticals in general cannot be captured by considering only one component of the grammar and the respective features of the parenthetical. As we have demonstrated, while syntax accounts for the parenthetical under investigation being attached to the node that dominates the numeral, pragmatics takes care of its position immediately preceding the numeral, and prosody explains the ungrammaticality of what in initial position. Moreover, parentheticals also have an exceptional status within the separate modules. For example, while they are a linear part of the syntactic structure of an utterance, they fail to be a constituent in its hierarchical structure. Similarly, while they are prosodically integrated in some ways, they are independent in other ways. Against this backdrop it comes as no surprise that in both syntax and prosody exceptional structures have previously been taken into consideration in order to account for the status of parentheticals. In syntactic theory, additional levels have been exploited (e.g. Safir's 1986 'LF-bar'), and otherwise unacceptable structures have been suggested (e.g. McCawley's 1982 'crossing branches'). In prosodic theory, the idea that even short parentheticals without pitch accent might form their own, anomalous prosodic domain is not foreign (e.g. Bing, 1985), even though their problematic status has been acknowledged by, for example, Cruttenden (1997: 36-7) and Wichmann (2001: 185). These ideas reflect the realization that to treat parentheticals as a pure discourse phenomenon would deny their occurrence within syntactic and/or prosodic strings. Our approach to parenthetical what is not completely without novel assumptions, either. For example, we introduce a 
feature-matching process and a NUM-searching feature that is unique to the parenthetical under investigation here. However, as far as syntax is concerned, as opposed to the nonintegrated type of analyses (e.g. Haegeman, 1988), our featurematching analysis can account for the relation between the host and the parenthetical, which is marked by simultaneous unintegratedness and relatedness, without dealing with parentheticals at the level of utterance interpretation only. As for prosody, the simultaneous presence of apparently contradictory features of the parenthetical being separate (in terms of overall pitch declination) and integrated (in terms of prosodic phrasing) is taken care of along the lines of CPD formation. Since syntactic, pragmatic, and prosodic features of parenthetical what all have their say in where it occurs on the surface, those aspects cannot be dealt with separately, and, specifically, parentheticals cannot be defined along syntactic lines only, as has most recently been suggested by Kaltenböck (2005). In this sense, the behaviour of what along with other kinds of parentheticals seems to challenge the idea of the autonomy or at least the central status of syntax, and an architecture of the grammar that has been dubbed by Jackendoff (2002) 'syntactocentric'. It has been noted previously (e.g. Burton-Roberts, 2006) that in syntactic theory, linear order is usually determined by hierarchical relations, and that in this sense parentheticals are problematic in a purely syntactic account. Taking all this into consideration, it seems as if Jackendoff's (2002) tripartite model, where the different generative components of the grammar work in a parallel fashion with relating interface systems, provides one way to account for the interaction of syntactic, pragmatic, and prosodic features as observed with parentheticals in general, and as outlined in detail for parenthetical what above. To say it with Jackendoff's words, 'language comprises a number of independent combinatorial systems, which are aligned with each other by means of a collection of interface systems' (Jackendoff, 2002: 111; his italics). Syntax is among the combinatorial systems, but so are phonology and conceptual structure. ${ }^{19}$ Parentheticals can then be seen as one example of a typical interface phenomenon. Crucially, in such a system, there are three interface systems relevant to the phenomenon under investigation: (i) syntax-phonology/prosody, (ii) syntax-pragmatics (conceptual structure), and (iii) phonology/prosody-pragmatics. At the syntax-prosody interface, e.g. the interference of the parenthetical with prosodic phrasing due to its linear position must be taken care of. The syntax-pragmatics interface accounts for the position of parenthetical what immediately preceding the numeral, thus restricting the linear order in the syntactic string. And, finally, the pragmatics-phonology/prosody interface is responsible for those intonational features of the parenthetical that are related to its pragmatic/interpretational status as an emphasizing, floor-keeping device.

19 Conceptual structure, according to Jackendoff (2002: 123), is 'part of thought' rather than part of language per se. 'It is the locus for the understanding of linguistic utterances in context, incorporating pragmatic considerations' and it is where 'reasoning and planning take place'. 
All in all, the present study of parenthetical what not only provides a comprehensive account of its behaviour and distribution, but it also serves as a contribution to the general discussion of parentheticals and their status within the grammar.

\author{
Author's address: \\ Freie Universität Berlin \\ Department of English Language, Literature and Culture \\ Gosslerstr 2-4 \\ 14195 Berlin \\ Germany \\ nicole@linguistics.ucl.ac.uk \\ Survey of English Usage \\ Department of English Language and Literature \\ University College London \\ Gower Street \\ London WC1E 6BT \\ ykavalova@gmail.com
}

\title{
References
}

Ackema, P. \& A. Neeleman (2004). Beyond morphology: interface conditions on word formation. Oxford: Oxford University Press.

Bing, J. M. (1985). Aspects of English prosody. New York and London: Garland.

Birner, B. J. \& G. Ward (1998). Information status and noncanonical word order in English. Studies in Language Companion Series 40. Amsterdam and Philadelphia: John Benjamins.

Blakemore, D. (1987). Semantic constraints on relevance. Oxford: Blackwell.

Blakemore, D. (1991). Performatives and parentheticals. Proceedings of the Aristotelian Society 91: 197-213.

Blakemore, D. (1992). Understanding utterances: an introduction to pragmatics. Oxford: Blackwell.

Blakemore, D. (2002). Relevance and linguistic meaning: the semantics and pragmatics of discourse markers. Cambridge: Cambridge University Press.

Blakemore, D. (2004). Discourse markers. In Horn, L. \& G. Ward (eds.), The handbook of pragmatics. Oxford: Blackwell. 221-40.

Bolinger, D. (1989). Intonation and its uses: melody in grammar and discourse. London: Arnold.

Brinton, L. (1996). Pragmatic markers in English: grammaticalisation and discourse functions. Berlin and New York: Mouton de Gruyter.

Burton-Roberts, N. (2006). Parentheticals. In Brown, K. (ed.-in-chief), Encyclopaedia of Language and Linguistics 2nd edition, vol. 9. Elsevier Science. 179-82.

Carston, R. (1999). The semantics-pragmatics distinction: a view from relevance theory. In Turner, K. (ed.), The semantics-pragmatics interface from different points of view. Amsterdam: Elsevier. 85-125.

Chomsky, N. (1995). The minimalist program. Cambridge, MA: MIT Press.

Cooper, W. \& J. Sorensen (1981). Fundamental frequency in sentence production. Heidelberg: Springer.

Corver, N. \& C. Thiersch (2002). Remarks on parentheticals. In van Oostendorp, M. \& E. Anagnostopoulou (eds.), Progress in grammar. Articles at the 20th anniversary of the Comparison of Grammatical Models Group in Tilburg. Online publication, available at http://www.meertens.knaw.nl/books/progressingrammar. 
Cruttenden, A. (1997). Intonation, 2nd edition. Cambridge: Cambridge University Press.

Emonds, J. (1973). Parenthetical clauses. In Corum, C., T. C. Smith-Stark \& A. Weiser (eds.), You take the high node and I'll take the low node. Chicago: Chicago Linguistic Society. 333-47.

Espinal, M. (1991). The representation of disjunct constituents. Language 67: 726-62.

Fagyal, Z. (2002). Prosodic boundaries in the vicinity of utterance-medial parentheticals in French. Probus 14: 93-111.

Gee, J. P. \& F. Grosjean (1983). Performance structures: a psycholinguistic and linguistic appraisal. Cognitive Psychology 15: 411-58.

Haegeman, L. (1988). Parenthetical adverbials: the radical orphanage approach. In Chiba, S., A. Shuki, A. Ogawa, Y. Fuiwara, N. Yamada, O. Koma \& T. Yagi (eds.), Aspects of modern linguistics: papers presented to Masatomo Ukaji on his 60th Birthday. Tokyo: Kaitakushi. 232-54.

Hoffmann, L. (1998). Parenthesen. Linguistische Berichte 175: 299-328.

Ifantidou, E. (2001). Evidentials and relevance. Amsterdam and Philadelphia: John Benjamins.

Jackendoff, R. (1977). $X^{\prime}$ syntax: a study of phrase structure. Cambridge, MA: MIT Press.

Jackendoff, R. (2002). Foundations of language: brain, meaning, grammar, evolution. Oxford: Oxford University Press.

Kaltenböck, G. (2005). Charting the boundaries of syntax: a taxonomy of spoken parenthetical clauses. Vienna English Working Papers 14: 21-53.

Kavalova, Y. (2004). Conceptual and procedural parentheticals in English. Paper presented at the 25th Conference of the International Computer Archive of Modern and Medieval English (ICAME 25). Verona, Italy, 19-23 May 2004.

König, E. (1991). The meaning of focus particles. London and New York: Routledge.

Ladd, D. R. (1986). Intonational phrasing: the case for recursive prosodic structure. Phonology Yearbook 3: 311-40.

Ladd, D. R. (1996). Intonational phonology. Cambridge: Cambridge University Press.

Levey, S. (2005). The sociolinguistic distribution of discourse marker LIKE in preadolescent speech. Ms., Queen Mary, University of London. To appear in Multilingua.

McCawley, J. D. (1982). Parentheticals and discontinuous constituent structure. Linguistic Inquiry 13: 91-106.

Nelson, G., S. Wallis \& B. Aarts (2002). Exploring natural language: working with the British component of the International Corpus of English. Amsterdam and Philadelphia: John Benjamins.

Nespor, M. \& I. Vogel (1986). Prosodic phonology. Studies in Generative Grammar 28. Dordrecht: Foris.

Peterson, P. (1999). On the boundaries of syntax. In Collins, P. \& D. Lee (eds.), The clause in English. Amsterdam: John Benjamins. 229-50.

Potts, C. (2002). The syntax and semantics of as-parentheticals. Natural Language and Linguistic Theory 20: 623-89.

Quirk, R., S. Greenbaum, G. Leech \& J. Svartvik (1985). A comprehensive grammar of the English language. Harlow: Longman.

Rooth, M. (1996). Focus. In Lappin, S. (ed.), The handbook of contemporary semantic theory. Oxford: Blackwell. 271-97.

Ross, J. R. (1973). Slifting. In Gross, M., M. Halle \& M.-P. Schützenberger (eds.), The formal analysis of natural languages. Proceedings of the first international conference. The Hague and Paris: Mouton. 133-69.

Safir, K. (1986). Relative clauses in a theory of binding and levels. Linguistic Inquiry 17: $663-89$. 
Selkirk, E. (1984). Phonology and syntax: the relation between sound and structure. Cambridge, MA: MIT Press.

Selkirk, E. (1986). On derived domains in sentence phonology. Phonology Yearbook 3: 371-405.

Selkirk, E. (1995). Sentence prosody: intonation, stress, and phrasing. In Goldsmith, J. A. (ed.), The handbook of phonological theory. Oxford: Blackwell. 550-69.

Selkirk, E. (1996). The prosodic structure of function words. In Morgan, J. L. \& K. Demuth (eds.), Signal to syntax: bootstrapping from speech to grammar in early acquisition. Mahwah, NJ: Lawrence Erlbaum. 187-213.

Shiffrin, D. (2003). Discourse markers: language, meaning and context. In Shiffrin, D., D. Tannen \& H. Hamilton (eds.), The handbook of discourse analysis. Oxford: Blackwell.

Sperber, D. \& D. Wilson (1986/1995). Relevance: communication and cognition. Oxford: Blackwell.

Taglicht, J. (1998). Constraints on intonational phrasing in English. Journal of Linguistics 34: 181-211.

Truckenbrodt, H. (1995). Phonological phrases: their relation to syntax, focus, and prominence. (Slightly revised version of) $\mathrm{PhD}$ dissertation, MIT.

Truckenbrodt, H. (1999). On the relation between syntactic phrases and phonological phrases. Linguistic Inquiry 30: 219-55.

Verschueren, J. (1999). Understanding pragmatics. London, New York, Sydney and Auckland: Arnold.

Ward, G. \& B. J. Birner (1995). Definiteness and the English existential. Language 71: 722-42.

Wichmann, A. (2000). Intonation in text and discourse: beginnings, middles and ends. Harlow: Longman.

Wichmann, A. (2001). Spoken parentheticals. In Aijmer, K.. (ed.), A wealth of English: studies in honour of Göran Kjellmer. Göteborg: Acta Universitatis Gothoburgensis. 177-93.

Zec, D. (2005). Prosodic differences among function words. Phonology 22: 77-112.

Zec, D. \& S. Inkelas (1990). Prosodically constrained syntax. In Inkelas, S. \& D. Zec (eds.), The phonology-syntax connection. Chicago and London: University of Chicago Press. 365-78. 